\title{
PRENSA Y PARTIDO EN EL REPUBLICANISMO PROGRESISTA: EL PORVENIR (1882-1885) ${ }^{1}$
}

PRESS AND PARTY IN PROGRESSIVE REPUBLICANISM: EL PORVENIR (1882-1885)

\author{
Eduardo Higueras Castañeda \\ Universidad de Castilla-La Mancha
}

Entregado el 12-3-2014 y aceptado el 17-10-2014.

\begin{abstract}
Resumen: El artículo propone un análisis conjunto de los aspectos discursivos, formales y económicos de un periódico político arquetípico de la Restauración. El Porvenir fue el órgano de Manuel Ruiz Zorrilla y del Partido Republicano Progresista. Se trata, por ello, de un periódico de partido y de oposición antimonárquica en una época en la que se impone la prensa independiente y de negocio. Constituye, por otra parte, un caso excepcional por haberse conservado su documentación financiera en el archivo privado de Ruiz Zorrilla. Estas fuentes inéditas convierten a El Porvenir en una herramienta para conocer en profundidad el sector periodístico desde el punto de vista económico, así como la relación de estos aspectos con los fines políticos que un periódico de sus características se proponía.
\end{abstract}

Palabras clave: España, S. XIX, historia de la prensa, republicanismo, Ruiz Zorrilla.

Abstract: This paper proposes a joint analysis of the discursive, formal and economic aspects of an archetypical political newspaper of the Monarchical

${ }^{1}$ Este trabajo se enmarca en el programa FPU del MEC (AP2009-2610), y del proyecto financiado por el MCINN: El republicanismo radical: anclajes sociológicos y significaciones populistas, 1854-1895 (HAR2010-16962). Asimismo, debo agradecer la atenta colaboración de los responsables de la Fundación Esquerdo y de su Archivo Histórico. 
restoration period in Spain. El Porvenir was the personal organ of Manuel Ruiz Zorrilla and the Republican Progressive Party. It is therefore a partisan and antimonarchical newspaper at a time when the independent and business press predominates. It is, moreover, an exceptional case due to the fact that its financial documentation had been preserved in the private archive of Ruiz Zorrilla. These unpublished sources make El Porvenir a tool to know the press industry in depth from an economical point of view, as well as the relationship of these aspects with the innate aims of a political newspaper.

Key words: Spain, XIX Century, press history, republicanism, Ruiz Zorrilla. 


\section{Introducción: un periódico tradicional en tiempos de cambio}

El Porvenir nació en un momento de profunda transformación para el sector periodístico en España. A comienzos de 1882, cuando su primer número apareció, la restrictiva Ley de 7 de enero de $1879^{2}$ estaba vigente. En 1883, sin embargo, la Ley de Policía de Imprenta marcó un hito en la evolución del marco normativo de la libertad de prensa, facilitando el desarrollo de nuevos proyectos periodísticos ${ }^{3}$. No por ello cesó el aluvión de multas y denuncias hasta su desaparición en septiembre de 1885. La «Ley Gullón» había eliminado los tribunales de Imprenta y remitía al Código Penal las infracciones de la prensa. Pero por más que se modificara la jurisdicción competente, discutir la forma de gobierno o la religión del Estado seguía siendo un acto punible ${ }^{4}$.

Esos mismos años fueron también cruciales en la evolución de la profesión periodística ${ }^{5}$. En torno a 1880 aparecen numerosas novedades que apuntan, precisamente, a la profesionalización del sector. La prensa tradicional de opinión cede terreno ante el periódico de información. Asoma el sensacionalismo. La publicidad se convierte en el factor clave para el sostenimiento de las cabeceras. Se prioriza la ganancia frente al rendimiento político. Así, la prensa de partido inicia una etapa de agotamiento, que no será ni mucho menos inmediato. Los periódicos «independientes» se consolidan: El Imparcial, El Liberal y La Correspondencia de España pugnan por el liderazgo en difusión y ventas que les permite, a la vez, conseguir mayores ingresos por línea o palabra de anuncios. Se apunta, en definitiva, a la apari-

2 Respecto al marco jurídico en materia de imprenta durante la Restauración, Vid. María López de Ramón, La construcción histórica de la libertad de prensa. Ley de Policía e Imprenta de 1883, Universidad Carlos III, Madrid, 2014; Juan Ignacio Marcuello Benedicto, «La libertad de imprenta y su marco legal en España», Ayer, 34, 1999, pp. 65-92; y Manuel Suárez Cortina, El gorro frigio. Liberalismo, Democracia y Republicanismo en la Restauración, Biblioteca Nueva, Madrid, 2000, pp. 69-70.

3 Carlos Soria, «La Ley española de Policía de Imprenta de 1883», Documentación de las ciencias de la información, 6, 1982,pp. 11-40. Sobre el impacto de la Ley Gullón en el número de publicaciones periódicas en Madrid, Vid. Jean-François Botrel, Libros, prensa y lectura en la España del siglo XIX, Pirámide, Madrid, 1993, pp. 367-379.

4 Vid. Sergio Sánchez Collantes, «La Electricidad Democrática. La prensa como agente dinamizador vivificante y cohesivo en el republicanismo español del XIX», en Enrique Bordería Ortiz, Francesc Martínez Gallego e Inmaculada Rius Sanchís (coord.), Política y comunicación en la historia contemporánea, Fragua, Madrid, 2010, pp. 383-399.

5 Vid. María Cruz Seoane y María Dolores Sáiz, Historia del periodismo en España, Vol. 2, Alianza, Madrid, 1983, pp. 254-262. 
ción de la prensa de masas (vinculada, claro está, al desarrollo de una sociedad de masas) y a su consolidación como sector económico autónomo ${ }^{6}$.

El Porvenir, en cambio, respondía a un modelo arquetípico de periódico tradicional: era el órgano oficial del Partido Republicano Progresista, una agrupación marcadamente personalista. Por ello, puede también caracterizarse como un órgano personal. Manuel Ruiz Zorrilla, desde su exilio en Francia, ejercía un liderazgo casi absoluto sobre esta agrupación ${ }^{7}$. A la vez, era propietario del periódico e inspirador de su línea política. En una publicación de estas características, ser suscriptor casi equivalía a ser militante. De este modo, la financiación del diario recaía, fundamentalmente, en el propio partido. Pero El Porvenir presenta desde su fundación ciertas peculiaridades que matizan esa caracterización. En primer lugar, Ruiz Zorrilla fijó como objetivo prioritario que el periódico fuera rentable. Por otra parte, las mismas inercias modernizadoras tan presentes en esa época forzaron su reestructuración empresarial para asegurar su viabilidad.

Poco tiempo después de aparecer, El Porvenir ya figuraba en sexto lugar en las listas de pago del derecho de timbre ${ }^{8}$. Conforme a este índice, antes de desaparecer en septiembre de 1885, ocupaba el quinto puesto en circulación. Sus cuatro años de existencia delimitan una trayectoria breve, pero más prolongada que la mayor parte de las cabeceras de este periodo 9 . Se trata por tanto de un periódico relevante en el contexto de la prensa española de la Restauración. La excepcionalidad de haberse conservado en el archivo privado de Manuel Ruiz Zorrilla una gran parte de su contabilidad (balances, contratos, listas de suscriptores y corresponsales, etc.) le confiere, además, un valor modélico para conocer en detalle la vida de una empresa

6 Jesús Timoteo Álvarez, Restauración y prensa de masas. Los engranajes de un sistema (1875-1883), Universidad de Navarra, Pamplona, 1981. p. 385; Juan Francisco Fuentes y Javier Fernández Sebastián, Historia del periodismo español, Síntesis, Madrid, 1998, pp. 144-151.

7 Sobre Manuel Ruiz Zorrilla, Vid. Jordi Canal, «Manuel Ruiz Zorrilla (1833-1895). De hombre de Estado a Conspirador compulsivo», en Isabel Burdiel y Manuel Pérez Ledesma (coord.), Liberales, agitadores y conspiradores, Espasa, Madrid, 2000, pp. 269-298; Fernando Martínez López, «La «Corte revolucionaria». Ruiz Zorrilla en París», en Fernando Martínez, Jordi Canal y Encarnación Lemus, París, ciudad de acogida. El exilio español durante los siglos XIX y XX, Marcial Pons, Madrid, 2010, pp. 113-157.

${ }^{8}$ Pagaba 1.221 pts. y se situaba inmediatamente después de La Iberia, muy por encima de periódicos consolidados como La Discusión, La Unión o La Época. El Porvenir, 20-5-1882.

9 Vid. Pedro Pascual, Escritores y editores en la restauración canovista (1875-1923), Vol. 1, Ediciones de la Torre, Madrid, 1994, pp. 319-320. 
periodística ${ }^{10}$. Al mismo tiempo, permite analizar las funciones del periódico y sus redactores en el marco partidario. Por último, ayuda a estudiar el discurso político y la penetración social de la agrupación que representaba.

\section{La prensa republicana progresista ante el inicio del turno de partidos}

El Partido Democrático-Progresista se constituyó entre 1879 y $1880^{11}$. Amalgamaba diversos núcleos que procedían, en su mayoría, del antiguo Partido Radical (Ruiz Zorrilla, Martos, Montero Ríos) y del republicanismo histórico (Salmerón, Muro, etc.). La agrupación no fue más que un débil enlace de tendencias divergentes, pese a que en abril de 1880 se logró acordar un programa común. Tras la formación del primer gobierno liberal de la Restauración en febrero de 1881, las diferencias latentes auguraban una completa ruptura. El sector encabezado por Martos trataba de imponer una línea «benévola» de expectación respecto al nuevo ministerio $^{12}$. En cambio, la tendencia mayoritaria era partidaria de la oposición a ultranza. En este contexto, Ruiz Zorrilla planificó unificar la prensa del partido en un solo órgano oficial. Así, esperaba reforzar su liderazgo, favorecer la unidad y atenuar las discrepancias.

El marqués de Montemar, representante de Zorrilla, elaboró en abril un presupuesto para fundar el periódico. Ascendía a 230.000 reales, que comprendían los gastos de propaganda e instalación. Además, planeaba comprar La Prensa Moderna y El Manifiesto, publicaciones a las que pretendía sustituir. La idea era contar con imprenta propia para lanzar «un gran periódico al precio de 10 rs. en Madrid y 12 en provincias». Para sostenerlo se calculaba «un total de gastos en el $1^{\text {er }}$ año de 240 a 300.000 rs.», debiéndose alcanzar las 7.000 suscripciones fijas durante dicho pe-

${ }^{10}$ Archivo Histórico de la Fundación Esquerdo, Archivo Manuel Ruiz Zorrilla [AHFE/ AMRZ], Exilio 42.

11 Miguel Artola, Partidos y programas políticos, Tomo I, Los partidos políticos, Aguilar, Madrid, 1977, p. 374.

12 «La política de expectación benévola se nos impone: la política pesimista sería nuestro descrédito», advertía Cristino Martos a Ruiz Zorrilla, (18-3-1881), AHFE/AMRZ, Exilio 9, C 56. Sobre la evolución del republicanismo progresista, Vid. Carlos Dardé, «La larga noche de la Restauración, 1875-1900», en Nigel Townson (ed.), El republicanismo en España (1830-1977), Madrid, Alianza Editorial, 1994, pp. 113-135; y Manuel Suárez Cortina, «Radicalismo y reformismo en la democracia española de la Restauración», Berceo, 139, 2000, pp. 49-66. 
riodo. Un mes más tarde, Pedro Fernández del Rincón corrigió el plan de Montemar. La previsión de gastos para la fundación se elevó a 252.000 rs. El desembolso estimado para 1882 se elevó hasta los 340.000 o 400.000 rs. Pero los acontecimientos obligaron a rebajar las expectativas y variar los objetivos políticos ${ }^{13}$.

En octubre se verificó la ruptura definitiva del sector martista, que se integró en una nueva agrupación: la Izquierda Dinástica. Encabezada por el duque de la Torre, fue la puerta por la que los disidentes del Partido Democrático-Progresista entraron en el campo monárquico ${ }^{14}$. En ese momento, fundar el periódico se convirtió en una necesidad urgente para frenar los efectos de la disidencia. En diciembre comenzaron los trabajos. Montemar realizó un último presupuesto, partiendo de una estimación de 6.000 suscriptores para 1882. Descontando la instalación, esperaba un déficit de 157.230 rs.:

El $3^{\text {er }}$ presupuesto en dic[iembre] se formó abandonando la idea de un periódico de gran tamaño: adoptando un término medio, y para hacerlo conciliable con la venta a 5 céntimos, y justificar al mismo tiempo el precio de 8 cs., superior a los otros diarios, se inventó lo del Semanario [de las Familias], única combinación posible. Aunque partía el Sr. Rincón de la base de su presupuesto de 17.000 a 20.000 duros como capital, la disidencia del mes de Octubre que podrá influir en la mayor o menor clientela del periódico, obligó a aquél y a Montemar a tomar la precaución del tamaño, a no tener por el momento imprenta propia, lo cual permitía una instalación en mejor punto ${ }^{15}$.

Zorrilla gestionó la fundación del periódico desde el exilio. En su nombre tres dirigentes del partido, Francisco de Paula Montemar, Pedro Fernández del Rincón y Carlos Diego Madrazo, actuaron en España. El primero tenía una larga experiencia periodística. Había sido redactor de La Nación y director de Las Novedades, uno de los principales periódicos progresistas del reinado de Isabel $\mathrm{II}^{16}$. Su función, sobre todo, era elegir a la redacción y

13 Madrazo a Ruiz Zorrilla (s/f, 1882), AHFE/AMRZ, Exilio 42, C 89.

${ }^{14}$ Miguel Artola, op. cit. pp. 335-336.

15 Madrazo a Ruiz Zorrilla (s/f, 1882), op. cit.

16 Eugenio Hartzenbusch, Apuntes para un catálogo de periódicos madrileños desde el año 1661 al 1870, Establecimiento Tipográfico «sucesores de Rivadeneyra», Madrid, 1894, pp. 121 y 129. Según Fernández de los Ríos, Montemar fue el principal autor de la hoja clandestina El Murciélago, que circuló en 1854. Ángel Fernández de los Ríos: Estudio histórico de las luchas políticas en la España del Siglo XIX, Tomo II, English y Gras Editores, Madrid, 1880, p. 345. 
supervisar sus trabajos. Carlos Madrazo carecía de esa experiencia. Como familiar de Ruiz Zorrilla y hombre de negocios tenía la confianza plena del jefe radical. Por eso le designó administrador de El Porvenir.

El primer escollo lo encontraron a la hora de negociar la compra de La Prensa Moderna. Su propietario, Joaquín Bañón, esperaba una compensación superior al valor real del periódico. Esgrimía su antigüedad ${ }^{17}$, la fidelidad a Ruiz Zorrilla, las denuncias sufridas, el esfuerzo y dinero invertido $^{18}$. Pero, sobre todo aspiraba a «una participación en el capital que la nueva empresa representase y una injerencia en la dirección y administración de la misma». Debe tenerse presente que la propiedad de un periódico militante garantizaba una significativa cuota de influencia en la agrupación: «Bañón no se resigna[ba] fácilmente a perder la consideración que le da la dirección de su periódico» ${ }^{19}$. El acuerdo no se $\operatorname{logró}^{20}$ y $L a$ Prensa Moderna siguió publicándose hasta 1885. No obstante, su propietario compró cinco acciones de El Porvenir ${ }^{21}$. No pusieron tantos problemas Valentín Morán y Santos de La Hoz, responsables de El Manifiesto, que desapareció ese mismo año ${ }^{22}$.

Prescindir de imprenta facilitaba elegir un punto para la instalación de la administración. Conforme al plan de Montemar y Rincón, se prefería una ubicación «ruidosa y de reclamo». Eligieron un local de la calle de Alcalá por el que pagaban 3.750 rs. al mes. Debe subrayarse que la administración

17 La Prensa Moderna sucedió en 1881 a La Nueva Prensa, aparecida en 1875.

18 Bañón cifraba en 20.000 rs. las ganancias mensuales de su periódico, y en 60.000 las máquinas, imprenta y otros valores. Afirmaba haber sufrido en esos años «cuarenta denuncias, tres supresiones [...] y varias causas criminales». Vid. Bañón a Madrazo y Pedro F. del Rincón, 28-12-1881; y Rincón a Bañón, 26-12-1881. Ambas en AHFE/AMRZ, VARV. 2, Bloque 5.

${ }_{19}$ Rincón a Ruiz Zorrilla, Madrid, 13-12-1881, AHFE/AMRZ, Exilio 42, C 89.

20 Rincón a Ruiz Zorrilla, Madrid, 1-1-1882, AHFE/AMRZ, VARV. 2, Bloque 5.

21 Carlos Madrazo a Ruiz Zorrilla, Madrid, 25-1-1882, AHFE/AMRZ, Exilio 42, C 52.

22 Según la anterior carta de Bañón, los propietarios de El Manifiesto le ofrecieron fundirlo con La Prensa Moderna. Sin embargo, dos dirigentes progresistas, Valentín Morán y Santos Lahoz, lo reclamaron «para sí en pago de algunos miles de reales que le habían prestado». En mayo de 1882 Madrazo dice a Zorrilla haberle «abonado los 12.000 rs. satisfechos a El Manifiesto». Madrazo a Ruiz Zorrilla, 23-5-1882, AHFE/ AMRZ, Exilio 42. Suárez Cortina liga su desaparición con la suspensión temporal decretada en 1881 por un Tribunal de Imprenta. Vid. Manuel Suárez Cortina, op. cit. p. 76. Lo más probable es que dicha suspensión no conllevara la liquidación de la empresa, pero facilitara su venta a Zorrilla. El Porvenir, de hecho, heredó los créditos pendientes de El Manifiesto. Vid. «Cuenta formada [...] el día 25 de Junio [de 1882]», AHFE/ AMRZ, Exilio 42, C 89. 
de un periódico no era sólo un centro de trabajo, sino un espacio de sociabilidad fundamental en toda agrupación política. El Porvenir debía proyectar la imagen de un partido vigoroso. La elevada concurrencia posibilitaba, además, la apertura de un salón de exposiciones. A través de la venta de cuadros esperaban sufragar una parte del elevado alquiler del local ${ }^{23}$.

En apenas un mes el periódico se puso en marcha. Se editaba 6 días por semana, de martes a domingo. Cada ejemplar costaba 5 céntimos. El precio de suscripción mensual en Madrid ascendía a 8 rs. En provincias, 30 por trimestre y 50 en el extranjero. Para su formato, se trataba de un periódico caro. El Imparcial y El Globo, por ejemplo, costaban 18 rs. el trimestre en Madrid y 24 en provincias ${ }^{24}$. Pesaba 30 gramos, lo mismo que $\mathrm{El} \mathrm{Si}$ glo Futuro y La Correspondencia de España ${ }^{25}$. Era un gramaje superior a la mayor parte de los restantes diarios. Para compensar el precio, los lunes se entregaba a los suscriptores El Semanario de las Familias, un suplemento ilustrado de 16 páginas. Su contenido era puramente didáctico y recreativo: literatura, arte, ciencia, industria, moda, etc. Pese a que se ofertaba por 6 reales mensuales en Madrid y 20 trimestrales en provincias, no llegó a contar con ningún suscriptor. Por ello, más que un reclamo, fue un lastre.

Publicitar un periódico, incentivar las suscripciones y la compra de acciones eran funciones que correspondían a los núcleos dirigentes de los partidos. La propia estructura de la agrupación (comités, prensa provincial, círculos, casinos o tertulias) y los lazos clientelares de sus notables eran instrumentalizados para este fin. De ahí que una posición económica elevada conllevara también una cierta jerarquía dentro del grupo. Las obligaciones de El Porvenir importaban 500 pesetas, que devengaban «un interés del cinco por ciento anual [...] reintegrables, cuando los beneficios del periódico lo permi[tieran]» ${ }^{26}$. Según refleja un informe de mayo de 1882, se habían colocado acciones por valor de 260.000 rs. Salvador López (80.000), Ruiz Zorrilla (50.000), Julián Prats y Ramón Orozco (20.000) eran los máximos inversores. Entre los restantes, son numerosos los parientes y los colaboradores más próximos de Zorrilla ${ }^{27}$.

23 «Nuestro salón», El Porvenir, 2-4-1882.

${ }^{24}$ Una comparativa de los precios de suscripción de diecisiete diarios en Jesús Timoteo Álvarez, op. cit. p. 132.

${ }_{25}$ Pesaba el doble que El Liberal, y 10 gr. más que El Imparcial o El Globo. Vid. Roger L. Utt, Textos y con-textos de Clarín. Los artículos de Leopoldo Alas en El Porvenir (Madrid, 1882), Istmo, Madrid, 1988, p. 15.

26 AHFE/AMRZ, Exilio 42, L 50.

27 Carlos Madrazo a Ruiz Zorrilla, (22-V-1882), AHFE/AMRZ, Exilio 42, C 89. 
También Nicolás Salmerón, la otra cabeza visible del partido, colaboró en esta tarea de propaganda. En realidad, por más que El Porvenir pretendiera ser el único portavoz de la agrupación, los seguidores del ex presidente de la República habían tenido poco que ver en su fundación. Entre Zorrilla y Salmerón existían importantes divergencias de doctrina y procedimiento, pero cara al público convenía negarlas ${ }^{28}$. Por eso accedió a enviar una carta para el primer número del periódico y a promocionarlo entre sus partidarios ${ }^{29}$. González Chermá, en papel timbrado de $\mathrm{El} \mathrm{Cla-}$ mor, periódico progresista alicantino, le contestó que:

tanto D. Mateo Asensi, distinguido catedrático, como yo, hemos hecho cuanto nos es dado escribiendo circulares a todos los pueblos de la provincia donde tenemos amigos. Pero lo cierto es que este país está esquilmado en demasía. Entre los rigores de la guerra civil carlista, el alzamiento cantonal con sus precisas emigraciones, 5 años de sequías, y ahora los insufribles tributos que nos agobian, y finalmente el que los demócratas, en su mayoría, somos pobres, es muy difícil hacer suscripciones, más cuando estas son a 30 rs. trimestre. Pero no por ello cejaremos: les recordaremos a los correligionarios el sistema de hacer entre varios una suscripción, habiéndose logrado ya varias ${ }^{30}$.

Pedro Coca, propietario de La Unión Democrática de Albacete, se comprometía a recomendar El Porvenir, advirtiendo que no era fácil sumar nuevas suscripciones: «sólo en Albacete habrá sus 30 [...], además de dos paquetes de 25 ejemplares que se venden por la calle». Esa era una cifra notable para «una población de 14.000 habitantes, en la que hay tres casinos, suscritos también al periódico, donde todo el mundo lo lee» ${ }^{31}$. La propaganda, por tanto, chocaba con diversos límites. En primer lugar, se sobrentiende la estrechez del público lector ${ }^{32}$. Por otra parte sólo podía contarse con los propios correligionarios. La existencia de otras cabeceras republicanas reducía aún más las posibilidades de

28 Fernando Martínez López, «Las enseñanzas del exilio. Nicolás Salmerón en París (1876-1885)», en Fernando Martínez López (ed.), Nicolás Salmerón y el republicanismo parlamentario, Biblioteca Nueva, Madrid, 2007, p. 107.

${ }^{29}$ En El Porvenir de 6-4-1882 se publicó una circular de Salmerón recomendando el periódico: «deber es de todos los republicanos responder a este nuevo esfuerzo del Sr. Ruiz Zorrilla».

30 González Chermá a Salmerón, 28-3-1882, AHFE/AMRZ, Exilio 37, C 84.

31 Pedro Coca a Salmerón, 30-3-1882, AHFE/AMRZ, Ibid.

32 Vid. Jean-François Botrel, op. cit. pp. 330-331. 
crecimiento. Además, parece claro que el perfil socioeconómico de un suscriptor de El Porvenir no era asimilable al de uno de La Época. Aunque no tanto como el conservador, el periódico radical era caro ${ }^{33}$. Desde este punto de vista, era complicado alcanzar las 6.000 suscripciones que Montemar y Rincón se habían propuesto para garantizar la viabilidad del diario.

El resultado de la propaganda, sin embargo, fue esperanzador. En enero El Porvenir tenía 2.066 suscriptores en provincias. Un mes más tarde, habían ascendido a 2.263. En Madrid se repartían a domicilio 749 ejemplares. En Granada, Burgos y Soria se obtuvieron los mejores resultados con más de un centenar de suscripciones ${ }^{34}$. Al fin y al cabo, Soria era la provincia de origen de Ruiz Zorrilla. En Burgos se concentraban la mayor parte de las propiedades de la familia de su mujer. Eran, por tanto, dos provincias donde el líder radical mantenía una fuerte influencia. Durante esos dos meses, en Madrid se vendieron diariamente en torno a 400 números sueltos. Más de 150 se repartían gratuitamente a teatros, centros oficiales y a colaboradores ${ }^{35}$.

El proyecto de diciembre de 1881, aunque rebajaba las expectativas de los anteriores, seguía siendo demasiado ambicioso. La cifra presupuestada para la redacción era de 4.300 rs. mensuales. A ellos debían sumarse 600 más por el servicio telegráfico. Todo ello es equiparable a lo invertido por otros periódicos. Sin embargo, el gasto estimado para colaboraciones era de 5.900 rs. Se trata de una partida que ni siquiera contemplaban cabeceras como El Siglo Futuro ${ }^{36}$. La redacción quedó conformada por Rafael Ginard de la Rosa, Ernesto de la Guardia, Pedro Ruiz Ávila, José Miralles, Joaquín Ardila, Aguilar y Adolfo González Orbón. Los cuatro primeros cobraban 700 rs. mensuales, si bien Ginard, como director, recibía un complemento de 200 rs. Los restantes ingresaban 600, 400 y 300 rs. respectivamente $^{37}$.

${ }^{33}$ La Época costaba 48 rs. el trimestre en Madrid y 50 rs. en provincias, según Jesús Timoteo Álvarez, op. cit. p. 132.

34 «Estado numérico del alta y baja ocurrida en la suscripción», (24-2-1882), AHFE/ AMRZ, Exilio 42, C 26.

35 Vid. «Índice de los cambios y de las personas que reciben gratis El Porvenir», AHFE/AMRZ, Exilio 42, L 88.

36 José Altabella, «Contabilidad y periodismo. Notas y cifras para un ensayo sobre la evolución económica de la prensa», separata de Gaceta de la Prensa Española, 1956, p. 6.

37 Un mes más tarde, Ernesto de La Guardia ya no figuraba en la redacción. Antonio Buenavida, se incorporó a los anteriores conservando su salario de 500 rs. al mes. 


\section{Un periódico para unir a un partido}

El Porvenir se concibió, obviamente, como un periódico de opinión política. En la distribución de las secciones se percibe la intención de integrar a todos los núcleos del partido. Por eso dedicaba una sección fija en la primera o segunda página a los corresponsales y periódicos de provincias. A través de ese espacio los comités informaban sobre la situación de la agrupación y denunciaban prácticas abusivas de caciques y autoridades. Asimismo, cubría con detalle las reuniones, debates y conferencias celebradas en centros de solidaridad partidaria de la agrupación, como el Casino Democrático-Progresista. Las extensas crónicas de dichas sesiones canalizaban para un mismo público contenidos doctrinales que arrancaban de tradiciones diversas ${ }^{38}$. De este modo el periódico daba cabida a las distintas voces del partido, ya provinieran del republicanismo histórico, del demokrausismo o del progresismo democrático.

La nómina de colaboradores fijos responde a la misma intención integradora: Felipe Picatoste ${ }^{39}$ e Ildefonso Trompeta ${ }^{40}$, por ejemplo, procedían del antiguo Partido Progresista. Tomás Rodríguez Pinilla era uno de los demócratas «cimbrios», seguidor de Cristino Martos, que se integraron en el Partido Radical en $1870^{41}$. Eduardo Chao, muy próximo a Nicolás Salmerón, había sido redactor de El Huracán, una de las primeras cabeceras republicanas en la prensa decimonónica ${ }^{42}$. En otra de ellas, El Peninsular, escribió Eusebio Asquerino ${ }^{43}$. Con sus firmas, El Porvenir enraizaba en

38 Sirvan de ejemplo las conferencias de Valentín Morán, Santos La Hoz o Pedregal en El Porvenir, 6-1-1882, 27-1-1882, 5-4-1882, 10-1-1882 y Urbano González Serrano, «El Kulturkamph. La lucha por la cultura», El Porvenir, 19-4-1882.

39 Picatoste había sido redactor de El Madrileño y director de Las Novedades según Eugenio Hartzenbusch, op. cit. pp. 129 y 193. Dirigió la Gaceta de Madrid en 1872. Fue, además, director de El Manifiesto. Vid. Nemesio Fernández Cuesta, «Felipe Picatoste», en Últimos escritos de Felipe Picatoste, Miguel Romero, Madrid, 1892, pp. 17-24.

40 Sus colaboraciones fueron compiladas en el folleto: Ildefonso Trompeta y Martín, La contribución industrial y de comercio. Artículos publicados en el diario democrático «El Porvenir», E. de la Riva, Madrid, 1882.

41 Vid. Rafael Serrano García, «Trayectoria política y perfil intelectual de un «cimbrio»: Tomás Rodríguez Pinilla (1815-1886)», Ayer, 68, (2007), pp. 167-191.

42 Vid. Manuel Curros Enríquez: Eduardo Chao (ex ministro de la República). Estudio Biográfico - Político, Madrid, Librería de Perlado, Sáez y Compañía, 1914.

43 Enrique Rodríguez Solís, Historia del Partido Republicano Español, Tomo II, Madrid, Imprenta de Fernando Cao y Domingo de Val, 1893, p. 278. 
los orígenes mismos del Partido Demócrata, aunque ambos habían militado en las filas de los progresistas puros durante la década de 1860.

Clarín, discípulo de Salmerón, ya era un crítico reputado en la prensa madrileña ${ }^{44}$. Su acento anticlerical estaba aún más pronunciado en las colaboraciones de José Nakens y Juan Vallejo, los redactores de El Motín ${ }^{45}$, representantes de un republicanismo de marcada orientación popular y radical. Su columna «En Serio y en Broma» fue la colaboración más duradera en el periódico. El tono populista de sus escritos fue crucial para comprender la evolución ideológica de la militancia republicana progresista hacia el radicalismo de fin de $\operatorname{siglo}^{46}$. A ello ayudaron también las colaboraciones de Antonio Aguayo, sacerdote granadino conocido desde 1865 por su crítica al neocatolicismo y a la jerarquía eclesiástica con su «Carta a los presbíteros españoles» ${ }^{47}$.

El elevado número de colaboradores y el afán de contentar a todos eran, de igual manera, un medio de competir con garantías con las restantes cabeceras republicanas. Como observa Jesús Timoteo Álvarez «la familia demócrata era un grupo de enorme potencia en el campo de la información», ya que «contaba con el mayor y más importante número de publicaciones ${ }^{48}$. De hecho, El Porvenir, aún siendo el órgano oficial del partido, tenía dos competidores directos dentro de su propia agrupación: La Prensa Moderna y El Progreso, fundado por Andrés Solís en 1880 .

A pesar de esa voluntad integradora, la principal línea política del periódico era la que marcaba su propietario. Él mismo se encargó de clarificarla en el primer número, aparecido el 1 de enero de 1882. En una carta dirigida a su representante, Montemar, le recordaba «el objeto que nos proponemos realizar, fundando el periódico»:

${ }^{44}$ Sobre la colaboración de Clarín en El Porvenir Vid. Roger L. Utt, op . cit.

45 Vid. Manuel Pérez Ledesma, «José Nakens (1841-1926): Pasión anticlerical y activismo republicano», en Isabel Burdiel y Manuel Pérez Ledesma, Liberales, agitadores y conspiradores. Biografías heterodoxas del siglo XIX, Madrid, Espasa, 2000, pp. 301-330.

${ }_{46}$ Completaban la nómina de colaboradores habituales Manuel Prieto y Prieto, Luis Simarro, Curros Enríquez, Hipólito Rodríguez Pinilla, Camilo Estruch, Tomás Pastrana, Escuder, J. M. García Álvarez y Gómez Ortiz. Vid. Carlos Madrazo a Ruiz Zorrilla, «Cuenta de gastos e ingresos en el mes de enero», (31-1-1882), y «Cuenta general de gastos e ingresos...», (28-2-1882) en AHFE/AMRZ, Exilio 42, C 89.

47 José Luis Molina Martínez, Anticlericalismo y literatura en el S. XIX, Universidad de Murcia, Murcia, 1998, p. 237.

48 Jesús Timoteo Álvarez, op. cit., p. 193. 
Tener un diario cuya existencia esté asegurada con independencia y con desahogo; procurar, indemnizando a los que se publican hoy en Madrid, que, a ser posible, sea el único que nos represente en la prensa; aconsejar que se defiendan en él las ideas de orden y de progreso a que he rendido culto toda mi vida, e intentar que, a la vez que sea el eco de nuestro gran partido, predique incesantemente la unión de los que comulgan en principios y conducta.

Estas líneas generales se desarrollaban en una serie de fines concretos. En primer lugar, «demostrar que el país no ha[bía] ganado nada con la restauración». Todo lo contrario: a su juicio, los partidarios de don Alfonso alentaron estratégicamente la rebelión carlista durante el Sexenio Democrático para derribar la democracia. A continuación debía «demostrar que los obstáculos tradicionales existen siempre para las ideas, y que nunca existieron para los hombres». Aludía a la llegada de Sagasta al poder y negaba la posibilidad de que desarrollara una política verdaderamente liberal. Para Zorrilla esos obstáculos tradicionales se concentraban en el «ultramontanismo, causa de todos nuestros atrasos». En definitiva, correspondía a $E l$ Porvenir una impugnación radical de la obra restauradora en su conjunto:

Demostrar que no existe moralidad en la administración, independencia en los tribunales, verdad en el sufragio, equidad en la distribución del impuesto; que no se ha creado ninguna nueva riqueza ni desarrollado la que existía, ni mejorado siquiera, después de seis años de paz, la condición de nuestro pueblo, apagando la sed comunista de obreros de los campos en ciertas provincias, o suavizando en otras las asperezas de la lucha entre el capital y el trabajo ${ }^{49}$.

Frente a la Restauración, reivindicaba la Revolución en un triple sentido: como el periodo histórico iniciado en 1868 con la Gloriosa; como estrategia para alcanzar el poder por la vía insurreccional y, a la vez, como proyecto de futuro que bebía del recuerdo del Sexenio. La «Septembrina» tiene una presencia constante y central en el periódico. El compromiso con la lucha revolucionaria para derrocar la dinastía y con el período democrático servía de referente para medir la consecuencia de los actores políticos. De ahí que se aprovechara toda ocasión de recordar los antecedentes revolucionarios y antiborbónicos de los constitucionales de Sagasta

49 Ruiz Zorrilla a Montemar, (16-12-1881), El Porvenir, 1-1-1882. La publicación de esta carta motivó la primera denuncia del periódico, Vid. «Nuestra denuncia», El Porvenir, 5-1-1882. 
y de los izquierdistas del general Serrano ${ }^{50}$. Como negativo de la misma imagen, se conseguía resaltar la consecuencia revolucionaria de los seguidores de Zorrilla sin necesidad de hacerla explícita. Recordar la Revolución de Septiembre, por otra parte, permitía a los redactores y colaboradores de El Porvenir esquivar los preceptos legales para hacer propaganda revolucionaria y atacar indirectamente a la monarquía.

A esa misma estrategia responden los numerosos artículos de efemérides y recuerdos históricos. En ellos se rememoraban, ante todo, los abusos de los monarcas absolutos y del fanatismo religioso, la lucha contra el Antiguo Régimen, los pronunciamientos del reinado de Fernando VII y de Isabel II, etc. Como sintetizó Ángel Duarte, «sin historia no hay republicanos» ${ }^{51}$ : los demócratas radicales construyeron un relato en el que su propia genealogía se anclaba en la tradición del antiguo partido progresista. De acuerdo a su orientación revolucionaria, edificaron un panteón para exaltar a Riego, Zurbano, Espartero o Prim ${ }^{52}$. Era el martirologio de la lucha contra la reacción reinterpretado en clave antimonárquica. Y en esa genealogía engarzaba el mismo Ruiz Zorrilla, presentado como primera víctima de la Restauración.

También de acuerdo a las intenciones declaradas de su inspirador, $E l$ Porvenir centró gran parte de sus artículos de fondo en la censura a la benevolencia y la condena, cuando no la burla, a sus exponentes ${ }^{53}$. Eran, sobre todo, los líderes de la Izquierda Dinástica, del Partido Posibilista y del Partido Fusionista los blancos de tales ataques ${ }^{54}$. La intención, lógicamente, era evitar nuevas defecciones desde el campo radical al dinástico. Zorrilla, por otra parte, prefería a los partidarios de Sagasta en la oposición. En primer lugar, porque los fusionistas podían ser una competencia reformista que en-

50 Como ejemplo, baste citar los siguientes artículos: «Los demócratas dinásticos», «Misterios», «Sagasta fusilado», «Perdiz en escabeche», «Metamorfosis de Martos», en El Porvenir, 21-5-1882, 23-5-1882, 29-1-1882, 31-5-1882 y 17-1-1884.

51 Ángel Duarte Montserrat, «Sin historia no hay republicanos», Historia Contemporánea, n. ${ }^{\circ} 37,2008$, pp. 321-342.

52 Manuel Prieto y Prieto, «Recuerdos históricos. El movimiento de las Cabezas de San Juan»; Pascual Millán, «Efemérides. 9 de enero de 1879», El Porvenir, 4 y 10-1-1882 y «22 de junio de 1866», en El Porvenir, 22-6-1884. Cada 28 o 29 de diciembre, el periódico dedicaba una esquela al general Prim en su portada, y un artículo recordando su lucha contra la dinastía. Vid. El Porvenir, 29-12-1882, 28-12-1883.

53 «¿A qué la benevolencia?», «Balaguer y los benévolos», El Porvenir, 4-1-1882, 10-1-1882.

54 Vid. «La Gran Parada», «Chambord y Sagasta», «Peores que los canovistas», «Sagasta contra Sagasta» y «La Revolución o el poder» en El Porvenir, 11-1-1882, 16-5-1882, 8-4-1882 y $27-12-1883$. 
sombreciera su propio programa. Además, porque en ese escenario era posible una colaboración con dichos sectores para conspirar contra la dinastía.

Promover la unión de todos los republicanos puede entenderse como la otra cara de una misma estrategia de demarcación política. Días después de salir a la luz, El Porvenir secundó la «Declaración de la prensa republicana ${ }^{55}$. Tras esta iniciativa se celebró en el Casino DemocráticoProgresista una «Asamblea de la prensa», con representación de El Porvenir y otros 15 periódicos de Madrid y provincias ${ }^{56}$. Todo ello preludiaba los intentos de unión republicana ensayados en las décadas siguientes ${ }^{57}$. Pero lo que verdaderamente interesaba a los seguidores de Ruiz Zorrilla era alcanzar la aquiescencia revolucionaria (esto es: conspirativa e insurreccional) de todas las familias del republicanismo ${ }^{58}$.

Las revistas de Instrucción Pública, Instrucción Política, Jurídica, Mercantil y Militar aparecían en tercera o cuarta plana. Esta última apostaba abiertamente por la defensa de las reformas en el ejército y la abolición de las quintas ${ }^{59}$. Su fin era claramente estratégico: los seguidores de Ruiz Zorrilla confiaban en el ejército como protagonista del cambio político. Por ello se postulaban como el único partido verdaderamente preocupado por la situación de los militares ${ }^{60}$. El objetivo era identificar pueblo y ejército con la República como horizonte emancipador: «nada más perjudicial $[. .$.$] que divorciar de la masa general de ciudadanos esa agrupa-$ ción que constituye la colectividad armada, que no debe ser considerada otra cosa que la nación bajo su aspecto defensivo» ${ }^{61}$.

A pesar del lógico predominio de la temática política, para los periódicos de 1880 era indispensable conceder cierto espacio a nuevas demandas de

55 El Porvenir, 6-1-1882. A mediados de febrero la apoyaban 50 periódicos de toda España. Vid. El Porvenir, 15-2-1882.

56 El Porvenir, 14-2-1882. En el mismo sentido: «¡A coaligarse!» y «Concordia republicana», El Porvenir, 21 y 22-7-1882.

57 El 11-12-1882, por ejemplo, El Porvenir dedicó sus dos primeras planas de forma íntegra a cubrir el «Meeting de Coalición Republicana» del día anterior. Al mismo propósito responde el énfasis en los homenajes a Estanislao Figueras tras su fallecimiento, «Homenaje a Figueras» y «La Manifestación», El Porvenir, 4-11-1883 y12-11-1883.

58 «Somos revolucionarios», «El voto o el fusil», El Porvenir, 10-2-1882 y 19-3-1884.

59 El Porvenir, 29-1-1882.

60 En 1885, El Resumen, periódico de la Izquierda Dinástica, insertaba la sección «El Mundo Militar» en clara competencia con los republicanos progresistas. Vid. Ana Boned Colera, «El Resumen: estudio de las bases culturales de un periódico de la Restauración», en Historia y Comunicación Social, n. ${ }^{\circ}$ 1, 1996, p. 248.

${ }^{61}$ El Porvenir, 12-1-1882. 
información. La crónica sensacionalista, por ejemplo, tenía cabida a través del servicio telegráfico y las revistas de tribunales nacionales y extranjeros. La descripción de crímenes escabrosos o incluso las noticias de tinte rosa ${ }^{62}$, aparecían en la tercera plana. Esporádicamente, se insertaban entrevistas ${ }^{63}$. Tampoco faltaban las inevitables secciones de toros, teatros y crítica literaria. Estos espacios fueron ganando importancia por defecto, al reducirse drásticamente las colaboraciones en 1883. La comprometida situación financiera del periódico obligaba a reducir gastos. Los contenidos de tipo político, didáctico o científico se resentían. A cambio, se facilitaba su viabilidad financiera.

\section{Las funciones de una redacción republicana: propaganda política y acción revolucionaria}

En 1882 la diferencia entre un periódico de partido y un periódico independiente, así como entre la prensa de opinión y la de información, estaba perfectamente clara. Los propios redactores de El Porvenir eran conscientes de su papel:

Nosotros, periodistas de partido y hombres políticos, que no hemos puesto jamás nuestra pluma al servicio del mercantilismo periodístico, ni mucho menos hemos dejado de correr las responsabilidades y los riesgos del partido, estamos en circunstancias que no pueden concurrir en los que, desde el cómodo campo de la independencia, sin riesgos y sin responsabilidades, sin formales compromisos de partido, se agitan en todas formas y en todo sentido ${ }^{64}$.

Aludían a El Liberal, reprochándole su falta de criterio político fijo. Sin embargo, esas declaraciones deben tomarse con cautela. Que los periodistas de El Porvenir tuvieran «formales compromisos de partido» no significa que la profesión periodística no se hubiera transformado. García Monfort, viejo dirigente progresista, observaba que en la redacción había «jóvenes de buen entendimiento y de mejor voluntad: laboriosos, que redactan admi-

62 A modo de ejemplo, Vid. «Comentarios de la prensa extranjera sobre el casamiento de Sarah Bernhardt», «Un parricidio y un suicidio», El Porvenir, 9-4-1882, 27-4-1882; el «Crimen de Santa María de las Hoyas» fue noticia desde el 4-11-1883 hasta el 3-12-1883; el 5-11-1883 apareció en primera plana.

63 «Un reporter en la embajada china», El Porvenir, 6-11-1883.

64 «A El Liberal», El Porvenir, 16-4-1882. 
rablemente», pero no tenían «esa pasión íntima, constante, vehemente, que identifica al escritor con la hoja a la que transmite todos los latidos de su corazón». Tras ese tono marcadamente romántico, comparaba a los periodistas de El Porvenir con las redacciones militantes de la década de 1860 y del Sexenio. Pero lo que más le extrañaba era «no ver a ninguno de los redactores por el Congreso ni por el salón de conferencias [...] que es el gran laboratorio de todo lo que en política nace o se inventa, se debate o comenta» ${ }^{65}$.

Según Montemar eran «literatos más que políticos y no van a ciertos centros, porque a las horas que les deja libres la redacción tienen que vivir también de sus trabajos literarios» ${ }^{66}$. En un sector económico tan débil como la industria editorial en esos años finales del S. XIX el periodismo, con pocas excepciones, era un oficio marginal. Esa intersección entre producción intelectual (un trabajo inestable y mal pagado) y militancia política de oposición, era una de las puertas del mundo bohemio. El joyero Ildefonso González, principal accionista de El Porvenir, no ocultó su desagrado a Ruiz Zorrilla después de visitar la redacción: «que más bien que una empresa periodística parecía un asilo de beneficencia» ${ }^{67}$. Montemar, como supervisor de los redactores, trató de solventar esa falta de compromiso político fomentando la sociabilidad partidaria en la redacción: «después de arreglar con los redactores políticos lo del día - explicaba - vienen los amigos, existiendo así un centro de actividad para estar al corriente de todo, como sucedía en la antigua Iberia. Es útil también esta reunión diaria para que los redactores estén más al corriente» ${ }^{6}$.

No era el caso de todos los redactores. Formar parte del periódico ayudaba a escalar en los cuadros dirigentes del partido. El Porvenir, como los restantes medios nacionales y provinciales vinculados al mismo, tenía representación nata en sus asambleas generales. Además, los periodistas más implicados poseían una clara ventaja para representar a sus provincias de origen $^{69}$. Varios directores de El Porvenir, como Ginard de la Rosa, Ruiz Ávila y José Miralles, se involucraron activamente en los trabajos de conspiración ${ }^{70}$. Ruiz Ávila tuvo un papel destacado en la rebelión militar de agosto de 1883.

\footnotetext{
65 García Monfort a Ruiz Zorrilla, 7-6-1883, AHFE/AMRZ, Exilio 8, C 75.

${ }^{66}$ Félix [Seud. Montemar] a Ruiz Zorrilla, 4-2-1883, Ibid.

67 Ildefonso González Amigo a Ruiz Zorilla, 9-4-1883, Exilio 42, C 90.

${ }^{68}$ Félix [Seud. Montemar] a Ruiz Zorrilla, 4-2-1883, Ibid..

69 Vid. Pedro F. del Rincón a Ruiz Zorrilla, 6-1-1883, Ibid..

70 Vid. Siffler-725 [Seud. Miguel Pérez]: Don Manuel Ruiz. Zorrilla ante la A.R.M., Imprenta de José de Rojas, Madrid, 1883, pp. 16, 51, 76 y 79.
} 
A finales de 1883 actuaba como segundo secretario de la Asociación Revolucionaria Militar ${ }^{71}$. Ginard se exilió para evitar la cárcel, al ser condenado por un tribunal militar ${ }^{72}$. Tras reunirse en Ginebra con Zorrilla, formó parte de su «oficina» revolucionaria. Miralles también huyó a Francia en $1884^{73}$.

Junto a sus funciones propagandísticas, El Porvenir se convirtió en una infraestructura revolucionaria. De ello daba cuenta el ministro de Estado, Segismundo Moret: «la redacción de El Porvenir es [...] el centro y el foco de toda conspiración, y desde ella dos o tres personas de confianza se encargan de repartir y comunicar los avisos y contraseñas, y de dar las órdenes». El periódico contaba con una red de corresponsales en provincias encargados de cobrar las suscripciones. Generalmente, se escogía a los miembros más notables o más activos de cada comité para desempeñar esa tarea. Así, el periódico era el centro de una correa de transmisión que comunicaba a Ruiz Zorrilla con todos los núcleos de la agrupación:

Por este medio se popularizan las ideas más ofensivas a la Monarquía y se transmite el espíritu de la conspiración animándose todas estas gentes mutuamente con esperanzas de un éxito próximo [...]. Y como el periódico El Porvenir tiene en muchas provincias otros periódicos que reproducen sus artículos y defienden sus ideas, se va formando así por todas partes entre aquellas clases de la sociedad que más dispuestas se hallan a tomar parte en los disturbios políticos porque teniendo poco que perder pueden siempre ganar algo una atmósfera en la cual se nutren los gérmenes de la sedición ${ }^{74}$.

Algunos de estos corresponsales tuvieron funciones de mayor alcance. El médico almeriense Ezequiel Sánchez, por ejemplo, fue el encargado de llevar a Badajoz las contraseñas para la sublevación de agosto de $1883^{75}$. El mismo papel desempeñó en La Rioja Juan Manuel Zapatero, corres-

71 «Asociación Republicana Militar y civil en Madrid», Archivo General de Palacio [AGP], Cajón 18, Exp. 2. Según Ossorio y Bernard, «tras una agitada existencia de lucha», Ruiz Ávila «tuvo que ingresar en un manicomio en junio de 1887». Falleció el año siguiente. Manuel Ossorio y Bernard, Ensayo de un catálogo de periodistas españoles del S. XIX, Imprenta de J. Palacios, Madrid, 1903, p. 400.

72 Rincón a Ruiz Zorrilla, s/f [noviembre de 1883], AHFE/AMRZ, Exilio 42, C 91. Las dos primeras condenas dictadas contra Ginard se publicaron en El Porvenir el 16-11-1883.

${ }^{73}$ Los dos siguieron cobrando como redactores de El Porvenir. Miralles a Ruiz Zorrilla (3-11-1884), AHFE/AMRZ, Exilio 42, C 52. Ginard firmaba con su inicial la columna «Desde Ginebra», Vid. El Porvenir, 5-3-1884.

74 «Informe del Sr. Moret a S. M. el Rey Alfonso XII sobre el Orden Público», marzo de 1884, AGP, Cajón 23, Exp. 7.

75 Madrazo a Ruiz Zorrilla, 27-7-1882, AHFE/AMRZ, Exilio 42, C 89. 
ponsal en Cervera y exiliado tras la rebelión de Santo Domingo de la Cal$\mathrm{zada}^{76}$. Una red subsidiaria de periódicos de provincias completaba el esfuerzo de propaganda, vinculando la realidad local con la protesta antimonárquica a nivel nacional ${ }^{77}$. De este modo, El Porvenir se convirtió en la principal herramienta de Ruiz Zorrilla para articular y controlar el partido. Mantenerla, sin embargo, exigía un importante esfuerzo.

\section{La financiación de un periódico de partido: 1882-1884}

Ruiz Zorrilla concibió El Porvenir como una empresa económicamente autónoma. Obviamente, todo periódico aspiraba a obtener ganancias. Pero la prensa de partido, en la práctica, no podía sobrevivir sin contar con el apoyo financiero de sus patronos políticos, de empresas afines o con subvenciones del gobierno. Las pérdidas se asumían como algo inevitable. Por supuesto, Zorrilla preveía un desequilibrio asociado a las inversiones iniciales hasta que el periódico se estabilizara. Pero los gastos de instalación no fueron el mayor problema de El Porvenir. Sus dos primeros años estuvieron lastrados por una serie de errores de planteamiento y, sobre todo, por la imposibilidad de contar con un sistema eficaz de reparto y recaudación.

Los balances que el administrador del periódico, Carlos Madrazo, enviaba a Ruiz Zorrilla durante los años 1882 y 1883 ayudan a ilustrar esos errores de planificación. Los cuadros que siguen se han elaborado a partir de dichos informes. Para calcular los ingresos no se han contabilizado ni el importe de las obligaciones, ni el de los «adelantos» recibidos para compensar el déficit. El objetivo es mostrar cuánto costaba mantener un periódico y la recaudación obtenida regularmente por suscripciones, ventas, publicidad, etc. Hay que tener en cuenta que las acciones y los préstamos recibidos se convierten en gastos al pagarse intereses y devolverse préstamos. A finales de 1883 esas sumas habían sido devueltas en su mayor parte, y los intereses se pagaban con regularidad.

El Porvenir arrancó con un déficit que llegó a su punto máximo en mayo de 1882. Los gastos alcanzaron los 95.000 rs. Los ingresos, sin embargo, no crecían al ritmo necesario. En cualquier caso, debe considerarse que determi-

\footnotetext{
76 «Relación de las cuentas de los corresponsales de provincias», en AHFE/AMRZ, Exilio 42, C 89.

77 De los 50 periódicos que habían suscrito los «Acuerdos de la Prensa Republicana», 31 eran demócrata-progresistas. De ellos, 29 se publicaban en provincias. «La Prensa Republicana», El Porvenir, 15-2-1882.
} 
nadas inversiones, como la compra de papel, no tenían un carácter mensual. Desde abril de 1883, por ejemplo, el alquiler del local se pagaba por trimestres. Otros pagos, como los de imprenta, se hacían en ocasiones con irregularidad. El descubierto de un mes se cargaba en los posteriores. Eso explica, en parte, las bruscas oscilaciones que se observan en la primera tabla.

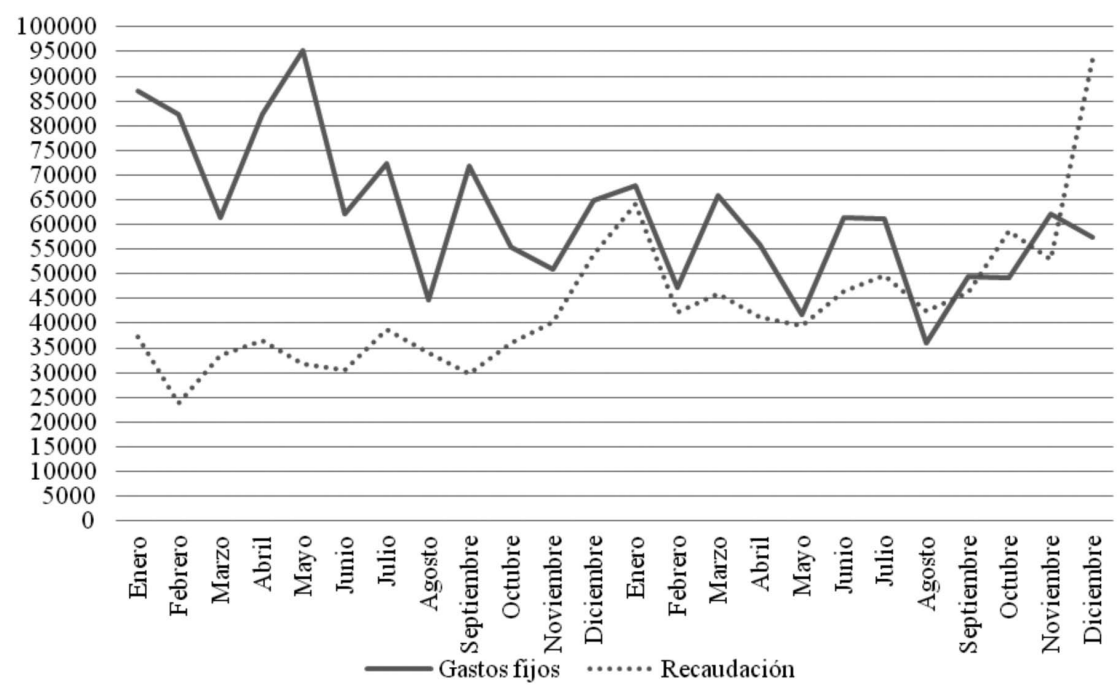

Tabla 1

Evolución de gastos fijos y recaudación 1882-1883

Fuente: AHFE/AMRZ, Exilio 42.

En mayo finalizó el periodo de instalación. Las reformas y el mobiliario para el local de la calle de Alcalá habían exigido un fuerte desembolso inicial. El enorme déficit que produjo fue solventado por los 102.000 rs. abonados entre enero y marzo por el comerciante Ildefonso González ${ }^{78}$. En cuanto a la recaudación, debe observarse que las suscripciones en pro-

$78 \mathrm{Vid}$. «Cuenta de gastos e ingresos», 21-1-1882 y 28-2-1882. Hasta abril de 1883, González Amigo había desembolsado 172.000 rs. para el periódico. González Amigo a Ruiz Zorrilla, 9-4-1883, AHFE/AMRZ, Exilio 42, C 90. En marzo se reformó el salón de exposiciones y se pagó la primera multa del periódico (de 342 rs.), según el balance de 31-3-1882, AHFE/AMRZ, Exilio 42, C. 89. 
vincias eran trimestrales, lo que explica la caída de los ingresos en febrero y su subida, de nuevo, un mes más tarde. En el primer semestre se habían superado las 4.000 suscripciones ${ }^{79}$. El crecimiento era rápido, pero insuficiente. Además, la venta de acciones no había tenido el éxito esperado. En mayo, el capital suscrito era de 246.000 rs., de los que ya se habían gastado $228.000^{80}$. Esta situación llevó a cuestionar por primera vez la viabilidad de la empresa. Según refería Madrazo:

No hay que pensar en que en muchos meses puedan igualar los gastos con los ingresos por muchos esfuerzos que hagamos, porque la miseria del país es grande, y para poder vivir de los propios recursos se necesitan 7.500 suscripciones [...]. Economías no encuentro donde hacerlas; en la redacción lo encuentro imposible porque los sueldos son pequeños, y se quejan además de que son pocos [...]. Lo único que puede desaparecer es la colaboración, casi por completo, pues sin ella podría marchar el periódico más bien más mal, pero marcharía [...]. Del papel, imprenta, correo, timbre, casa y fajas no se puede suprimir nada, así como gastos de cobranza y recibos fallidos [...]. Como ya te indiqué este mes se acaban todos los fondos de las obligaciones, y si la recaudación $[\ldots]$ no corresponde bien, a principios del mes próximo nos encontraremos sin poder pagar las primeras atenciones ${ }^{81}$.

En realidad sí era posible reducir los gastos a que se refería. Al comparar sus gastos con los de El Liberal, Madrazo se percató de que los planteamientos iniciales eran erróneos: «sólo en el papel que es de 15 gramos [...] y no habiendo puesto semanario, y la suscripción a 6 rs. tendríamos mucha más suscripción, y a estas horas estaríamos en ganancias». Pero eso no era todo. La partida destinada a colaboraciones estaba sobredimensionada. En noviembre de 1883, el gasto de colaboración era de 1.460 rs. En octubre y en diciembre, sólo se gastaron $240^{82}$. Además, los 3.750 rs. de renta por el local eran inasumibles. La venta de cuadros apenas produjo 420 rs. durante todo el año. El salón era claramente deficitario.

79 Montemar a Ruiz Zorrilla, 19-10-1882, AHFE/AMRZ, Ibid.

80 Madrazo a Ruiz Zorrilla, 23-5-1882, Ibid.

81 Carlos Madrazo a Ruiz Zorrilla, 12-5-1882, AHFE/AMRZ, Exilio 42, C 89. Más optimista era Montemar, que aconsejaba paciencia: «el resultado obtenido en un año, y aún en el tiempo ya transcurrido es grande comparado con el de las demás publicaciones, cuyo capital empleado es superior. Al estado floreciente o de cubrir gastos no llegan las demás empresas ni en uno ni en dos años», Montemar a Ruiz Zorrilla, 19-10-1882, Ibid.

82 Madrazo a Ruiz Zorrilla, 30-11-1883 y 31-12-1883, AHFE/AMRZ, Exilio 42, C 92. 
Tabla 2

Estimación de gastos mensuales de El Porvenir

\begin{tabular}{lrc}
\hline \multicolumn{1}{c}{ Concepto } & Reales & $\%$ del total \\
\hline 221 resmas de papel a 69 rs. cada una para 26 días & 15.249 & $24,21 \%$ \\
Timbre & 4.522 & $7,18 \%$ \\
Impresión y tirada & 16.640 & $26,42 \%$ \\
Administración y criados & 3.160 & $5 \%$ \\
Redacción & 4.100 & $6,5 \%$ \\
Colaboración & 3.660 & $5,8 \%$ \\
Corresponsal de París & 1.000 & $1,58 \%$ \\
Alquiler de Casa & 3.750 & $5,95 \%$ \\
Alumbrado & 600 & $0,95 \%$ \\
Reparto y cierre & 2.400 & $3,8 \%$ \\
Mozos & 224 & $0,35 \%$ \\
Gastos generales incluso el correo de ultramar, extranjero & 1.500 & $2,38 \%$ \\
y correspondencia & & \\
Objetos de escritorio & 500 & $0,79 \%$ \\
Fajas impresas & 966 & $1,53 \%$ \\
Para partidas fallidas y quebrantos de giro & 4.691 & $7,45 \%$ \\
\hline Suma & \multicolumn{2}{c}{62.962} \\
\hline
\end{tabular}

Fuente: AHFE, AMRZ, Exilio 42, C $89^{83}$.

Con las anteriores prevenciones, el administrador diseñó un nuevo presupuesto para El Porvenir. Merece la pena detenerse en él, puesto que parte de precios, salarios y expectativas de ingresos reales. Por ello es un buen resumen de los balances anteriores. La base de su cálculo eran 5.000 suscriptores (1.000 en Madrid), 500 menos de los que entonces tenían. Además, preveía 3.000 ventas diarias.

Incluyendo el semanario, el gasto ascendía hasta 70.592 rs. Los ingresos previstos (contando sólo 1.500 rs. por anuncios) sumaban 59.536 rs. El déficit seguía siendo de 10.056 rs. Madrazo no tenía demasiada fe en los anuncios como una vía para disminuirlo ${ }^{84}$, pero no la descuidó: «pro-

${ }^{83}$ Los cálculos en la tabla original contemplan una separación de los gastos según se trate de la edición para Madrid o la de provincias. Se ha optado por sumarlo para clarificar el cuadro.

84 «No te hagas muchas ilusiones con la 4 . $^{\mathrm{a}}$ plana, que si bien puede ayudar mucho, no puede pasar de 3 o 4000 rs. en todo su apogeo», le indicaba Madrazo a Ruiz Zorrilla, (22-6-1882, AHFE/AMRZ, Exilio 42, C 89. 
curo que no disminuya el importe del Timbre que es lo que nos ha de dar anuncios» ${ }^{85}$. La competencia por escalar las listas del pago del impuesto es una de las principales señales de modernización en la prensa de esta época. Desde la segunda quincena de enero, el periódico comenzó a poblarse de anuncios ${ }^{86}$. A partir de mediados de febrero, se cubrían con regularidad dos tercios de la cuarta página. La recaudación por este concepto, sin embargo, era sumamente irregular. En julio tenían una media de 8 anuncios. Ese mes marcó un punto de inflexión en el que se percibe un incremento lento, pero constante, en los ingresos por publicidad.

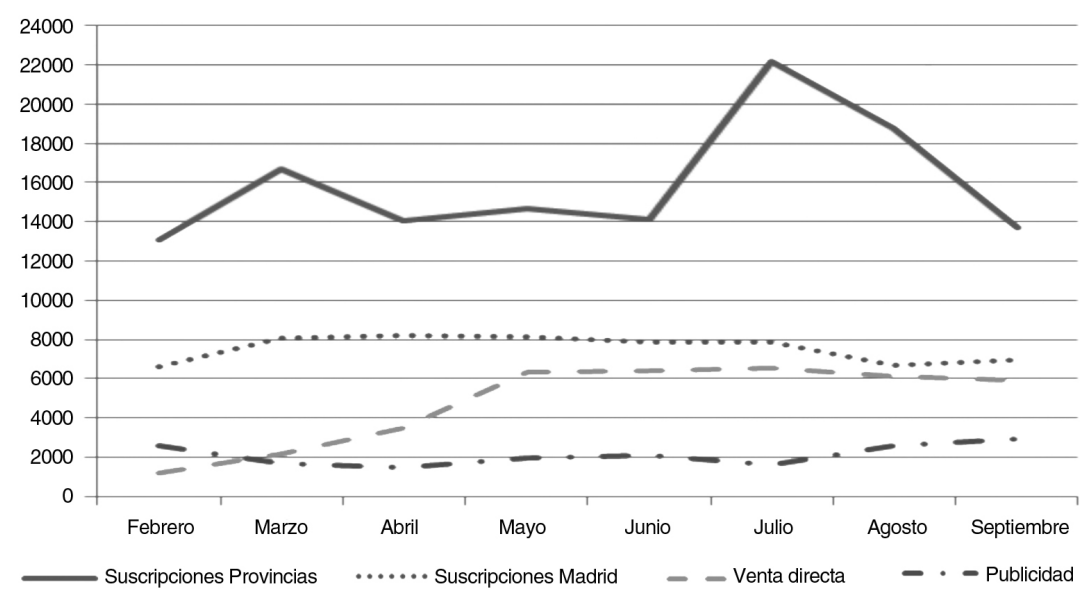

Tabla 3

Recaudación de El Porvenir entre febrero y septiembre de 1882

Fuente: AHFE/AMRZ, Exilio $42^{87}$.

Durante varios meses se había tratado de evitar que el periódico se sometiera a las condiciones de las sociedades de anuncios españolas ${ }^{88}$. El

85 Madrazo a Ruiz Zorrilla, 14-6-1882, en AHFE/AMRZ, Exilio 42, C 89.

${ }^{86}$ Aparecen por primera vez en El Porvenir, 15-1-1882.

${ }^{87}$ Para simplificar el gráfico, se han sumado las suscripciones a domicilio de Madrid con las del centro de suscripciones de la Puerta del Sol, y se han eliminado los ingresos extraordinarios, generalmente poco significativos. En enero, octubre y noviembre de 1882 , los balances sólo indican la recaudación total.

$88 \ll$ Se trabajan los anuncios, pero estos los tienen casi acaparados la sociedad de anuncios, y quedan pocos sueltos para los Periódicos independientes», Madrazo a Ruiz Zorrilla, 6-8-1882, Exilio 42, C 89. 
Porvenir debía consolidarse y buscar la mayor circulación posible para negociar en un escenario favorable. Mientras tanto, era preferible buscar anunciantes independientes. En septiembre la situación financiera obligó a alcanzar un acuerdo con la agencia de C. A. Saavedra. El contrato le reconocía «el derecho exclusivo de recibir para El Porvenir e insertar en su 4. a o 3 . plana $[\ldots]$ los anuncios y reclamos [...] relativos a cualquiera de los ramos del comercio, artes o industria extranjeros, sociedades financieras o de seguros, Bancos, etc». Por su parte, la agencia se obligaba «a pagar al Sr. D. Carlos Madrazo a razón de nueve céntimos de peseta por línea de anuncios, un mínimum anual de cinco mil cuatrocientas pesetas». Esa cantidad, aunque marcase un mínimo, representaba tan sólo un $25{ }^{\prime} 8 \%$ de lo que $L a$ Época ingresaba en 1886 por anuncios extranjeros ${ }^{89}$. El Porvenir se reservaba el derecho a incrementar el precio conforme aumentara la tirada:

Queda convenido que se aumentará el precio de la línea de anuncios, de un céntimo de peseta por cada cien pesetas más que pague $E l$ Porvenir por derecho de timbre, sobre las mil cien pesetas que paga al hacer este contrato $[\ldots]$. De la misma manera y en iguales condiciones disminuirá de un céntimo de peseta el precio de la línea de anuncios, por cada cien pesetas que pague El Porvenir de menos de la cantidad que por timbre satisface, al hacerse este contrato ${ }^{90}$.

Los ingresos por publicidad se incrementaron desde entonces, pero no de una forma decisiva. En diciembre se completaba toda la cuarta plana con un promedio de 22 anuncios. En la tercera ya eran frecuentes las esquelas, los reclamos y la publicidad «disimulada ${ }^{91}$. La recaudación por este concepto a fin de mes, sin embargo, sólo era de 4.054 rs. En enero del año siguiente ascendía a 5.825 rs., apenas un $8 \%$ de los ingresos tota$\operatorname{les}^{92}$. Madrazo era claro en este sentido:

me parece que debe ser una filfa lo que me dices de dar 24.000 rs. la Sociedad [General de Anuncios] de Calzado al Globo y al Liberal pues no tienes más que ver la cuarta plana de los dos y particularmente el último apenas trae anuncios. Y yo tengo preguntado a diferentes periódicos por segunda persona lo que llevan por línea [...] y aunque trajeran llena la cuarta plana

89 José Altabella, op. cit. p. 8.

90 El contrato con las adiciones se conserva en AHFE/AMRZ, Exilio 42, C 27.

${ }_{91}$ Un análisis de la publicidad y sus tipologías durante la Restauración, Vid. Jesús Timoteo Álvarez, op. cit. pp. 110-131.

${ }_{92}$ Los balances de diciembre de 1882 y enero de 1883 en AHFE/AMRZ, Exilio 42, C 90. 
no podían subir esta cantidad; sólo La Correspondencia y El Imparcial por su gran tirada y por su antigüedad pueden sacar mucha más cantidad [...] y esto con las muchas papeletas de defunción que valen un dineral, comunicados, referencias y sueltos pero de ninguna manera de los anuncios que poco más o menos los precios son iguales en cuasi todos los periódicos ${ }^{93}$.

La inexperiencia, por otra parte, les costó una pérdida sustancial de ingresos. Al negociar con Saavedra, habían tomado «por fijo la anchura de las columnas de la primera plana de 70 centímetros», pese a que en la cuarta, como casi todos los restantes periódicos, tenían una columna más. Ese detalle significaba un $20 \%$ de la recaudación por publicidad ${ }^{94}$. El verdadero soporte económico del periódico, por tanto, eran las suscripciones. Las tablas 3 y 4 permiten observar su peso en relación a la publicidad, la venta directa y otros ingresos extraordinarios (ventas de papel viejo, cuadros, etc.). En este sentido, cabe diferenciar entre las de Madrid y las de provincias, donde el precio era más caro. Estas últimas solían reportar el doble que las primeras. Sin embargo, la proporción de suscriptores muestra una relación muy diferente: de los 4.504 que existían en abril de 1883, sólo 794 eran de la capital ${ }^{95}$. El 17,6\% de las suscripciones, por tanto, aportaban entre la mitad y un tercio de los ingresos por este concepto.

En segundo lugar, frente a la estabilidad de los ingresos provenientes de Madrid, contrasta la gran inestabilidad de los de provincias. El motivo fundamental tiene que ver con el sistema de cobros y entregas a través de corresponsales. Ese era el principal talón de Aquiles del periódico: la administración carecía de medios eficaces para «cobrar corrientemente las suscripciones», dada la dificultad de «tener corresponsales económicos, y porque aún teniéndolos, e[ra] lento el cobro de la suscripción de las provincias que se encuentran muy repartidas» ${ }^{96}$. Esta era la preocupación constante de Madrazo: «los corresponsales que teníamos buenos se co-

93 Madrazo a Ruiz Zorrilla, (5-7-1882), AHFE/AMRZ, Exilio 42, C 89.

94 Madrazo a Ruiz Zorrilla, (11-12-1882), AHFE/AMRZ, Exilio 42, C 90.

95 «Resumen del movimiento de suscriptores durante el mes de abril», AHFE/AMRZ, Exilio 42, C 90. Ese porcentaje, por otra parte, está muy alejado del que habitualmente se estima para las cabeceras de este periodo: un $40 \%$ de venta en Madrid y un $60 \%$ en provincias. Vid. Josep-Francesc Valls: Prensa y burguesía en el XIX español, Anthropos, Barcelona, 1988, p. 45.

${ }_{96}$ Pedro F. del Rincón a Ruiz Zorrilla, 27-9-1882, AHFE/AMRZ, Exilio 42, C 89. Según Madrazo, «la recaudación en provincias se hace muy pesada porque los corresponsales se les hace muy difícil el cobrar en los pueblos pequeños», Madrazo a Ruiz Zorrilla, 3-9-1882, AHFE/AMRZ, Exilio 42, C 89. 
noce que se van cansando al ver la dificultad que tienen para el cobro y no sirven ni cartas fuertes ni cartas suaves, ni volantes a los suscriptores $\gg^{97}$. Una parte fundamental de los ingresos dependía, en última instancia, de la capacidad o el compromiso del corresponsal. Esta tarea, sólo ocasionalmente remunerada, era en última instancia una función política voluntaria. Dependía de la disponibilidad de militantes decididos que, además, pudieran recorrer poblaciones de toda la provincia de forma frecuente. Por ello, los cambios de corresponsal eran constantes.

En torno al sector periodístico ya se desarrollaban nuevos tipos de empresa como las agencias telegráficas o de anuncios. También hubo propuestas de profesionalización para responder a este problema. En abril de 1882, Madrazo recibió una oferta de Leopoldo Calzado. Le ofrecía «un servicio completo de corresponsales-verdad hasta en el último pueblo de la Península con objeto de poder recaudar la suscripción de los periódicos de todos en el más breve plazo posible» ${ }^{98}$. Para ello se apoyaba en los «poderosos medios que pone a mi disposición la Sociedad General de Anuncios». Varios directores de periódicos de Madrid le habían indicado esa necesidad. Madrazo recabó informes sobre la empresa de Calzado: «según tengo entendido es una farsa que promete mucho y no da nada, tanto que con todos los periódicos con que había contratado han roto el compromiso» ${ }^{99}$.

Era, por tanto, un problema generalizado. La solución pasaba por la profesionalización del servicio. Pero los primeros intentos para lograrlo resultaron un fiasco. Madrazo rechazó la oferta: El Porvenir, explicaba, era un «órgano de un partido, y los presidentes de todos los comités de España, son nuestros corresponsales». Por ello no era posible «retirarles una confianza que $[\ldots]$ tiene que ser absoluta y completa ${ }^{100}$. La respuesta era una media verdad, pero daba en el clavo: El Porvenir, a través de su administrador, de sus directores y de los corresponsales, era una correa de transmisión que vertebraba al partido. Su propia naturaleza era incompatible con un grado suficiente de profesionalización que garantizara una recaudación eficaz.

Zorrilla no logró, como había planeado, que el periódico fuera rentable: aunque a finales de 1883 la recaudación se equilibró con los gastos fijos, la devolución de préstamos y el pago de intereses seguían provocando un ba-

97 Madrazo a Ruiz Zorrilla, 24-4-1883, AHFE/AMRZ, Exilio 42, C 90.

98 Leopoldo Calzado a Madrazo, 25-4-1882, Exilio 42, C 89.

99 Madrazo a Ruiz Zorrilla, 19-4-1882, Ibid.

100 Sin firma y sin fecha, adjunta a la carta de Leopoldo Calzado a Madrazo, 25-4-1882, AHFE/AMRZ, Exilio 42, C 89. 
lance negativo. La respuesta inmediata fueron los recortes en colaboraciones, administración y en gastos de alquiler. El Semanario dejó de editarse. En su lugar, El Porvenir sacaba un número los lunes en un solo pliego. La administración se mudó a un local más económico. A todo ello debía añadirse la bajada generalizada de ingresos por suscripción entre agosto y septiembre por el veraneo, que obligaban a un sobresfuerzo para recuperarlas durante el otoño. Los cuadros 3 y 4 permiten observar ese fenómeno. En cambio, la fuerte caída de ingresos en agosto 1883 fue provocada por el movimiento insurreccional de 1883. Algunos de los corresponsales estaban implicados en su preparación y tuvieron que huir o esconderse ${ }^{101}$.

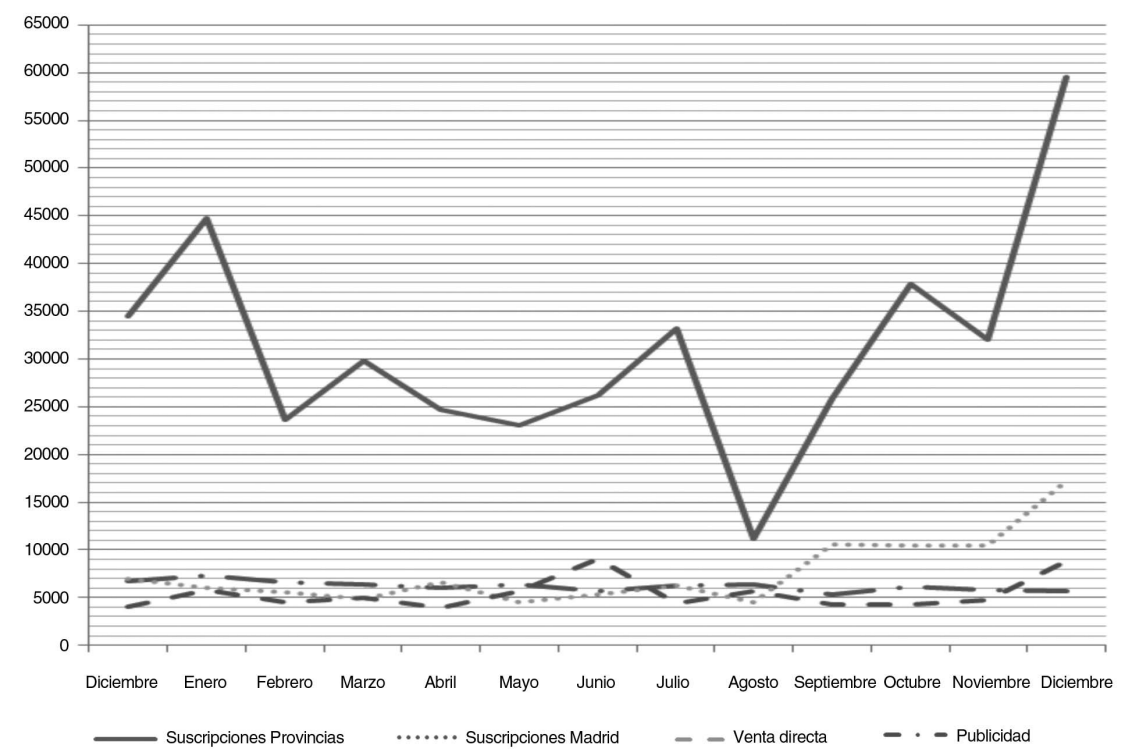

Tabla 4

Recaudación de El Porvenir entre diciembre de 1882 y diciembre de 1883. Fuente: AHFE/AMRZ, Exilio 42.

101 Sobre las sublevaciones de agosto de $1883 \mathrm{Vid}$. Eduardo Higueras Castañeda, «Militares republicanos en la Restauración: de la rebelión al exilio (1883-1891)», Trocadero, 25, 2013, pp. 35-55; Eduardo González Calleja, La razón de la fuerza. Orden público, subversión y violencia política en la España de la Restauración (1875-1917), Madrid, CSIC, 1998, pp. 103-125. 
Lo más interesante, sin embargo, es la fuerte subida de ingresos que se percibe en noviembre. Uno de los motivos pudo ser el cobro de atrasos en las suscripciones. Pero el aumento también se produce en publicidad y venta directa, lo que indica que hubo un incremento en la circulación del periódico. La razón principal, paradójicamente, fue también la rebelión de agosto. Ese mismo mes se descubrió la existencia de la Asociación Republicana Militar y su gran extensión entre la oficialidad ${ }^{102}$. Esta vasta agrupación clandestina, bajo los auspicios de Ruiz Zorrilla, había sido la responsable de las últimas insurrecciones. Todo ello repercutió directamente en la credibilidad de Zorrilla como jefe revolucionario: había demostrado que contaba con fuerza en el ejército. Ante la inactividad insurreccional de los restantes líderes republicanos, su actitud combativa e intransigente ganó peso en la opinión antimonárquica. El propio periódico había sido denunciado como instrumento de la insurrección. Por ello, las sublevaciones de Badajoz, Santo Domingo de la Calzada y la Seo de Urgel fueron su mejor propaganda.

\section{Hacia un nuevo modelo empresarial: 1883-1885}

La recaudación en los dos últimos meses de 1883 permitió pagar atrasos, devolver adelantos y satisfacer los intereses por obligaciones. El déficit acumulado era algo superior a los $50.000 \mathrm{rs}^{103}$. El impresor, además, había «prometido tirar el periódico por 480 rs. los 8.000 ejemplares», lo que significaba una bajada notable de precio. Estaba, por ello, en condiciones de empezar a dar ganancias. Sin embargo, Ruiz Zorrilla tenía decidido iniciar un giro en su gestión, sustituyendo Madrazo por un administrador con mayor conocimiento del negocio periodístico. Eduardo Medina se ofreció para el puesto con una propuesta que reducía considerablemente los gastos:

Casa -800 .

Cierre y reparto -1.200 .

Imprenta 30 días a 17 duros día - 10.200.

Papel 30 días -10.200 .

Timbre - 5000.

Corresponsal (París) -1.000 .

102 Vid. La Época y El Imparcial del 19-10-1883.

103 Madrazo a Ruiz Zorrilla, 5-11-1883, AHFE/AMRZ, Exilio 42, C 91. 
Redacción (Incluso lo del Sr. Medina) - 5000.

Administración - 1500 .

Imprevistos - 1100 .

Suma: $36.000^{104}$.

Esta decisión provocó un intenso debate en el seno de la redacción y del partido ${ }^{105}$. Medina carecía de historia política. Quienes lo conocían, afirmaban que se inclinaba más por opiniones moderadas que republicanas ${ }^{106}$. En cambio, tenía una larga trayectoria periodística: había dirigido durante nueve años La Correspondencia de España. Junto a Luis Navarro Calvo fundó la casa editorial Medina y Navarro Editores, en la que publicó La Revista Europea y La Crónica de la Música ${ }^{107}$. Pese a la resistencia de los dirigentes del partido, Zorrilla optó por confiar en Medina. A fines de 1883 su perspectiva sobre el futuro del periódico era optimista: «desde Octubre ha desaparecido el déficit y la suscripción sigue aumentando - le explicaba a María Buschental-, no puedes formarte idea de los sinsabores que me ha producido, de los compromisos en que me he puesto» ${ }^{108}$.

Dado que el papel y la imprenta sumaban el 50\% de los gastos, toda medida eficaz de ahorro debía concentrarse en esos dos conceptos. En este sentido, Medina consiguió una rebaja del impresor, que se comprometió a hacer «diez mil números del periódico por diez y nueve duros diarios». Anteriormente costaba «la tirada de ocho mil quinientos números unos veinte duros» ${ }^{109}$. Al mismo tiempo, se decidió reducir el grosor del papel y publicar una edición de menor formato para la venta directa. El periódico comenzó a tirarse de día. Para enviar los ejemplares a provincias con el correo de la tarde, se fijó a la redacción un horario de ocho a una de la mañana «y por la noche un par de horas, para preparar trabajos del día siguiente». El objetivo era mejorar el reparto a los suscriptores de provincias, «que son los que más ayudan» ${ }^{110}$. La administración, de nuevo, se trasladó a un local más

104 Constante [Seud. Ruano] a Ruiz Zorrilla, 20-5-1883, Ibid.

105 Ginard de la Rosa a Ruiz Zorrilla, 29-10-1883; P. del Rincón a Ruiz Zorrilla, 8-11-1883 y Cristóbal a Ruiz Zorrilla, 17-11-1883, Ibid.

106 Madrazo a Ruiz Zorrilla, 5-11-1883, AHFE/AMRZ, Ibid.

107 Manuel Ossorio Bernard, op. cit. p. 270.

108 Ruiz Zorrilla a María [Pereira de Buschental], s/f, [1883], AGP, Cajón 18, Exp. 1.

109 Constante [Ruano] a Ruiz Zorrilla, 17-2-1884, AHFE/AMRZ, Exilio 42, C 92.

110 El 9-3-1884 El Porvenir anunciaba la reorganización del servicio de reparto, y la intención de que los suscriptores recibieran el periódico antes de las 10 de la mañana. 
barato. Las suscripciones cuyo pago era irregular fueron canceladas, aunque las cifras totales se mantuvieron en los primeros meses de 1884 .

Pero los enfrentamientos surgidos en el seno de la redacción perjudicaron la marcha de El Porvenir. Ávila, Peña, Campomanes y otros periodistas fueron despedidos, quedando Figuls, Ardila y Pastrana como únicos redactores ${ }^{111}$. En abril, Tomás Rodríguez Pinilla se hizo cargo de la dirección: «voy a hablar a Vd. del periódico - le escribió a Ruiz Zorrilla-, está caído, muy caído. Sólo el nombre de Vd. y su prestigio le han podido sostener. La redacción es deficiente y todo pobre». Para solucionarlo, consideraba que faltaban «uno o dos redactores de punta; noticias telegráficas de última hora; una correspondencia semanal de Londres y otra de París; un periódico inglés que no tiene, y dos o tres franceses que le faltan, un folleto decente y atractivo para el bello sexo; y nada más». Todo ello podía significar una inversión de 3.000 rs.: «los producirá con creces el aumento de la suscripción» ${ }^{112}$ - suponía.

En la primavera de 1884 El Porvenir recuperó su lugar habitual en la lista del timbre, e incluso escaló posiciones durante los meses siguientes ${ }^{113}$. Moret informó al rey que El Porvenir: «gracias a la circulación que ha llegado, cubre su presupuesto y empezará a dejar recursos quizás en este semestre» ${ }^{114}$. Dado que la cuarta plana ya se llenaba regularmente de anuncios, se potenció la tercera ${ }^{115}$. La nueva administración no dudó en introducir publicidad indirecta en primera plana ${ }^{116}$. Cabe, por tanto, suponer que en 1884 por fin se había logrado el ansiado equilibrio económico. Pero eso no significa que Ruiz Zorrilla se hubiera librado de la carga que el periódico significaba para él. Por esas fechas declaraba a un correligionario:

111 Cristóbal a Ruiz Zorrilla, 5-4-1885, AHFE/AMRZ, Exilio 13, C 156. Durante 1884 Eduardo de la Peña y Curros Enríquez ayudaron a suplir las bajas, aunque no pertenecieron permanentemente a la plantilla de El Porvenir. Cristóbal a Ruiz Zorrilla, 10-10-1885, AHFE/AMRZ, Exilio 14, C 66.

112 Tomás Rodríguez Pinilla a Ruiz Zorrilla, 12-4-1885, AHFE/AMRZ, Exilio 13, C 156.

113 En julio de 1884 pagaba 1301 pts. y se situaba en quinta posición, según El Porvenir, 20-8-1884. En septiembre reclamaba esa quinta plaza, que sería la primera «entre los diarios exclusivamente políticos», frente a un rival también republicano radical, El Progreso. El Porvenir, 19 y 10-9-1884.

114 «Informe del Sr. Moret» op. cit.

115 Aparecen, por ejemplo, tres anuncios en el número del 4-1-1883.

116 Vid. El Porvenir, 16-6-1884 y «Expedición a Gaviria», en el número del 18-6-1884. Dicho balneario era un anunciante habitual del periódico. 
estoy cansado de las amarguras, disgustos y desembolsos que me cuesta desde su fundación. Las mismas pequeñeces y miserias que hubo entre las dos antiguas emes ${ }^{117}$ existen entre las dos actuales y estoy resuelto en consecuencia a que apretando en unos cuantos números condenen otros dos o tres nuevos directores y desaparezca el periódico anunciando que la tiranía del Gobierno no me permite tener un órgano propio. No faltará alguno de los actuales periódicos, o de los que se funden con mi apoyo indirecto, que defienda nuestra política, con lo cual podré destinar los recursos que empleo en el sostenimiento de El Porvenir a objetos más útiles y necesidades más apremiantes ${ }^{118}$.

A pesar del agotamiento de su propietario, El Porvenir se siguió imprimiendo diez meses más, a lo largo de los cuales hubo nuevos cambios. Si Medina acercó el periódico al deseado equilibrio financiero, no consiguió, en cambio, ganar la confianza del partido ni de la redacción. Por ello, a mediados de 1885 Víctor Zurita, uno de los hombres fuertes de la agrupación, se hizo cargo de la administración ${ }^{119}$. Su gestión, sin embargo, fue breve. La calidad del periódico había decaído preocupantemente. En mayo, Rodríguez Pinilla se mostraba agotado. En su opinión, debía buscarse «un personal de redacción competente y útil», cosa que no era posible con los recursos de que disponían: «con los elementos que hoy tiene y con los escasos que ofrece la administración el periódico no puede levantarse, no debe existir» ${ }^{120}$. Zorrilla decidió cortar por lo sano. El Porvenir había costado dinero, compromisos, polémicas, denuncias, destierros y causas en sede penal y militar $^{121}$.

Pero es posible suponer que su desaparición se debiera, además del desaliento, a una cuestión de oportunidad. Después de cuatro años, $E l$ Porvenir era una empresa estable con un número elevado de suscriptores. En esos años otro periódico vinculado al partido, El Progreso, había alcanzado cotas muy próximas en circulación. Cabía, por tanto, la posibilidad de fundir ambos periódicos, de manera que El Progreso se convirtiera en nuevo órgano del partido y de su líder. Por eso Ruiz Zorrilla

117 Es probable que se refiriera a Madrazo y Montemar. Respecto a «las dos actuales», debía hablar de Medina y Miralles.

118 Ruiz Zorrilla a 6 y 8, 29-11-1884, AGP, Cajón 26, Exp. 1/A.

119 Santos de la Hoz a Ruiz Zorrilla, 11-8-1885, AHFE/AMRZ, Exilio 16, C 21.

120 Rodríguez Pinilla a Ruiz Zorrilla, 4-5-1885, AHFE, AMRZ, Exilio 15, C 158.

121 «De ochenta a cien denuncias, con sus correspondientes procesos, contamos en nuestra vida», El Porvenir, 30-9-1885. 
traspasó El Porvenir «con todos sus derechos y obligaciones» a Andrés Solís, propietario de aquél. Solís, a su vez, reconoció «en favor de D. Manuel Ruiz Zorrilla la mitad de la propiedad en el periódico El Progreso». El líder revolucionario renunció a un $10 \%$ de beneficio en reconocimiento «del trabajo personal del Sr. Solís». Se pactaba, además, que «el Sr. Ruiz Zorrilla tendr[ía] la intervención que se acuerde entre ambos en la administración de el periódico». Para ello, podía nombrar un representante a sueldo de El Progreso. La dirección política quedaba a cargo de Andrés Solís, pero «siempre dentro de la política y de la conducta que el Sr. Ruiz Zorrilla defiende» ${ }^{122}$.

\section{Independencia política y rentabilidad: un difícil equilibrio}

El Porvenir apareció entre la prensa española de la década de 1880 con el paso cambiado. Los mismos fenómenos renovadores que se manifestaban en el sector obligaron a sus responsables a tratar de coger el ritmo de las cabeceras más punteras. Pero por sus propias características, la sincronía completa era imposible. Encontrar un modelo intermedio entre la prensa de partido y la prensa de negocio era difícil. El Porvenir, al fin y al cabo, tenía unos fines políticos muy determinados: sostener en la opinión pública la lucha revolucionaria contra la Restauración.

Uno de los principales puntos débiles del sector periodístico era el sistema de entregas y recaudación en provincias. La mayor parte de la prensa nacional se editaba en Madrid, donde el cobro era sencillo. Pero su público, por lo general, vivía en provincias. La población seguía concentrándose, mayoritariamente, fuera de las capitales. El sistema de corresponsales era, como mucho, semiprofesional. Esto obstaculizaba la circulación y producía grandes pérdidas por impagos, que socavaban la viabilidad de muchos periódicos. La elevada competencia, el monopolio de las sociedades de anuncios, la estrechez del público lector y las limitadas posibilidades económicas del mismo impedían el despegue definitivo del sector. Un buen conocedor del negocio periodístico expresaba a Ruiz Zorrilla su escepticismo sobre la las perspectivas de El Porvenir:

No recuerdo ningún periódico que exclusivamente de su aceptación pública se sostenga. Hay periódicos inteligentemente hechos y adminis-

122 «Cesión de El Porvenir», Londres, 15-9-1885, AHFE/AMRZ, Exilio 42, C 52. 
trados (como El Liberal) que no cubren sus gastos y lleva muchos años ya de publicación. Casi todos viven, si viven sin deudas, de subvenciones u otros medios a que El Porvenir no puede acudir. El periódico es pobre en cuanto a los medios de fortuna y resulta un periódico caro aquí donde hay muchos periódicos que se prestan a perder en la suscripción y en la venta con tal de sostenerse por otras útiles empresas. El Porvenir dando beneficios me parece una cosa muy difícil; la aspiración debe limitarse a sostenerse y mejorarse ${ }^{123}$.

Su conclusión era clara: ni siquiera los periódicos independientes de mayor circulación podían sobrevivir sin la ayuda de las subvenciones de la administración o de grupos de presión. El Porvenir nunca acudió a ellos. Todo lo contrario que uno de sus sucesores de mayor renombre: $E l$ Paí $^{124}$. Cuando en 1897 José María Esquerdo, heredero político de Ruiz Zorrilla, trató de lanzar El Progreso (bajo la dirección de Alejandro Lerroux) se topó con esa realidad: la prensa de partido no podía ser al mismo tiempo independiente y rentable. Algunos años más tarde, Esquerdo recordaba la advertencia que Zorrilla le hizo: "“Si usted aceptara la jefatura del partido cuando yo muera, jamás tome parte en empresas de fundación de periódicos", y me refirió la serie de disgustos que le trajo El Porvenir» ${ }^{125}$.

123 Rincón a Ruiz Zorrilla, Madrid, 14-11-1883, AHFE/AMRZ, Exilio 42, C 91.

124 Sobre el uso de los «fondos de reptiles», Jesús Timoteo Álvarez, «La estructura subterránea de la prensa en la Restauración», en Luis Enrique Otero Carvajal y Ángel Bahamonde Magro (eds.), Madrid en la sociedad del siglo XIX, Vol. 1., Alfoz, Madrid, 1986, 229-248. Para el caso de El País, Vid. José Álvarez Junco, El Emperador del Paralelo. Lerroux y la demagogia populista, Alianza Editorial, Madrid, 1990, pp. 59-63.

125 José María Esquerdo a Antonio, 25-12-1911, AHFE, Fondo José M. a Esquerdo Zaragoza: Fondo B. 